\title{
Problem Formulations, Solving Strategies, Implementation Methods \& Applications of Selective Harmonic Elimination for Multilevel Converters
}

\author{
Gireesh Kumar Devineni, Aman Ganesh* \\ SEEE, Lovely Professional University, Phagwara, Punjab 144411, India
}

Corresponding Author Email: aman.23332@1pu.co.in

https://doi.org/10.18280/jesa.530620

Received: 30 August 2020

Accepted: 28 November 2020

\section{Keywords:}

multilevel converters, PWM formulations, SHEPWM, optimization algorithms, solving techniques

\begin{abstract}
Multilevel converters are commonly recommended for converting DC power to AC as per load requirements owing to several advantages such as common mode voltage, less distorted input current, low switching frequency and reduced THD. However, the reliability, performance and efficiency of MLIs depend in particular on the switching technique used. The Selective Harmonic Elimination PWM approach is more efficient among existing modulation techniques to remove undesired harmonics from the output of MLI, since it operates at low switching frequency, particularly at fundamental frequency. The fundamental switching frequency operation of SHEPWM reduce the switching losses and improves inverter efficiency. The principal problem, however, is the empirical approach to non-linear equations. Numerous algorithms have been developed and implemented over the last decades including computational approaches, analytical methods, algebraic methods and optimization algorithms to solve the SHE equations and to eliminate the unintended harmonics. This article presented various aspects of SHE problem formulations, the comprehensive philosophy of operation of various SHE problem-solving approaches and the application of multilevel inverters. PWM waveforms, with single and multiple transitions, are examined and shown at each voltage level for solution frameworks that suit multiple solutions for pulse width modulation to allow researchers gain a deeper understanding and solution of SHE problems.
\end{abstract}

\section{INTRODUCTION}

For the applications including solar PV systems, FACTS, HVDC transmission, electric motor drives etc., sinusoidal voltages are desirable $[1,2]$. In addition, major developments in power electronics have significantly stimulated work into the construction of advanced multilevel inverters [3]. Multilevel inverters have major benefits against traditional two and three level inverters, such as small unit size, reduced harmonic distortion (THD) owing to stepped wave output and modular structure. Despite many benefits, the main problem with multi-level converters would be that its AC voltage generates unwanted harmonics [4]. The presence of undesired harmonics raises converter switching loss, reduces the efficiency [5]. The switching modulation strategy employed for the operation of the inverter has a significant influence on its output and performance. Numerous pulse-width modulation (PWM) strategies have been developed for MLIs such as high frequency modulation schemes like sine pulse modulation, phase shifted multi carrier modulation, fundamental frequency modulation schemes like selective harmonic elimination (SHE-PWM) and space vector modulation. From the above mentioned PWM schemes, the SHEPWM method exhibits superior control of unnecessary low-order harmonic suppression while maintaining the required voltage [6]. SHE-PWM switching scheme improves the efficiency with low frequency operation compared to certain typical carrier dependent PWM techniques and reduces filter unit size and rating [7]. The SHE-strategy's concept is to develop a set of dynamic, nonlinear transcendental equations in terms of trigonometric variables to obtain optimum switching angles [8]. As switching angles and degree of freedom increases, the real time, approaches to this problem are becoming increasingly complicated. The entire range of pre-determined firing angles is preserved in a lookup table in this case, so that the inverter can work across wide range of frequencies [9]. The number of potential harmonics that can be removed while simultaneously regulating the fundamental component depends on the degree of freedom.

The problem with the multilevel converters is its switching frequency which is the principal cause of harmonics and switching losses there by reduction in inverter's efficiency. To overcome this problem, it's convenient to operate the inverter at low switching frequency (i.e., at fundamental switching frequency) by SHEPWM. Further, the formulation of SHE equations and their solutions are the serious questions. The formulation of SHE-PWM equations depends on various inverter performance properties, the harmonics to be removed, and the modulation scheme developed. Several researchers investigated and reported PWM structures considering bipolar switching [10], unipolar switching [11], and multilevel switching [12]. It also evaluated and reported waveform effects such as QWS and HWS on inverter efficiency and workable solution space $[10,13]$. Because of the SHE-PWM formulation, several solutions set can be found which make it difficult to choose a superior solution [14]. Moreover, owing to the difficulty of SHE-PWM calculations or incorrect initial assumptions, converge to an ideal solution can often be several 
algebraic and numerical methods were proposed to solve equations such as the resultant theory [15] and NewtonRaphson method [16]. The problem with the N-R approach is that the solution convergence to the global minimum relies on the right initial values of the switching angles [17]. Throughout recent years, researchers proposed evolutionary methodologies such as genetic algorithm (GA) $[18,19]$ and particle swarm optimization (PSO) $[20,21]$ to solve SHE problems. Evolutionary algorithms primarily aim at achieving optimal firing angles for Multilevel converters to reduce the predefined fitness function of selected problem. The section-3 'SHEPWM Solution Techniques' contains detailed review on many influential SHE approaches for problem solving.

The article also provides a detailed description of the different techniques and algorithms used to solve SHE mathematical equations and allow investigators and determine the right strategy based on the size and specification of the inverter. The study therefore offers an in-depth review of the various SHE-PWM algorithms and the choice of the best solutions if several solution sets are available. The purpose of this article is to include all the insights and advice needed to successfully create and solve SHE problems using the best approach.

\section{SELECTIVE HARMONIC ELIMINATION PWM PROBLEM FORMULATIONS}

Husmukh and Richard invented selective harmonic elimination PWM strategy in 1973. The concept is that the basic output of the square wave is "chopped" repeatedly. The chopped interval is correlated to the set of semiconductors switching angles produced by correct off-line metrics. The inverter's output waveform is regulated by an appropriate switching angle distribution to turn on and off the inverter bridge switches, and the aim is to remove the reduced-order harmonics. In the case of carrier-based PWM techniques, where switching times are calculated by direct contrast with reference and carrier waves, where as in SHE-PWM the exact switching instants are calculated by Fourier representation of the switching pattern with the elimination of undesired harmonic components $[5,6]$. Owing to the complexity of the solving the Fourier equations of SHE-PWM, the quantity of switching angles is supposed to be held limited to simplify the calculations. This will reduce converter switching losses and use offline computations to track switching instants.

Two-level and high-level voltage source converters are controlled by SHEPWM [7, 8]. In two-level converters + Vdc and - Vdc voltage pulses are used for each half-period named as bipolar switching, although in three-level only either $+\mathrm{Vdc}$ or - Vdc is used for each half-period, named as uni-polar switching. Usually, a synthesized SHE VSC output waveform is built to have Quarter Wave Symmetry (QWS). One of the single-phase waveforms is defined in the expansion of the Fourier series and described by Eq. (1):

$$
V(\omega t)=a_{0}+\sum_{n=1}^{\infty} a_{n} \cos \left(2 \pi f_{0} n t\right)+b_{n} \sin \left(2 \pi f_{0} n t\right)
$$

where,

$\mathrm{f}_{0}=$ Frequency of fundamental component;

$\mathrm{n}=$ Harmonic order;

$\omega=2 \pi f_{0}$.
The equation can then be rewritten as:

$$
v(\omega t)=a_{0}+\sum_{n=1}^{\infty} a_{n} \cos (\omega n t)+b_{n} \sin (\omega n t)
$$

The coefficients of the above Fourier expansion $a_{0}, a_{n}, b_{n}$ can be determined from the following Eqns. (3), (4) and (5):

$$
\begin{gathered}
a_{0}=\frac{1}{2 \pi} \int_{0}^{2 \pi} V_{d c} d_{\omega t} \\
a_{n}=\frac{1}{\pi} \int_{0}^{2 \pi} V_{d c} \cos (n \omega t) d_{\omega t} \\
b_{n}=\frac{1}{\pi} \int_{0}^{2 \pi} V_{d c} \sin (n \omega t) d_{\omega t}
\end{gathered}
$$

The Eq. (2) can also be written as Eq. (6):

$$
v(\omega t)=a_{0}+\sum_{n=1}^{\infty} c_{n} \sin \left(\omega n t+\varphi_{n}\right)
$$

where,

$$
\begin{aligned}
& a_{n}=c_{n} \sin \varphi_{n} ; \\
& b_{n}=c_{n} \cos \varphi_{n} ; \\
& c_{n}=\sqrt{a_{n}^{2}+b_{n}^{2}} ; \\
& \varphi_{n}=\tan ^{-1}\left(\frac{a_{n}}{b_{n}}\right) \text { for } b_{n}>0 ; \\
& \varphi_{n}=\tan ^{-1}\left(\frac{a_{n}}{b_{n}}\right)+180^{0} \text { for } b_{n}<0 .
\end{aligned}
$$

\subsection{Three phase symmetry}

The waveforms of converter output need a three-phase symmetry to balance the total harmonics for effective operation of loads. This helps reduce line voltages in the event of triplen harmonics inside a three-phase network. 3PS with 3phase voltages is needed and appropriate phase shift by $120^{\circ}$. The phase voltages with positive sequence by $120^{\circ}$ phase shifts is represented in Eq. (7).

$$
\begin{aligned}
& \mathrm{v}_{\mathrm{a}}\left(\omega \mathrm{t}+\frac{2 \pi}{3}\right)=\mathrm{v}_{\mathrm{c}}(\omega \mathrm{t}) \\
& \mathrm{v}_{\mathrm{b}}\left(\omega \mathrm{t}+\frac{2 \pi}{3}\right)=\mathrm{v}_{\mathrm{a}}(\omega \mathrm{t}) \\
& \mathrm{v}_{\mathrm{c}}\left(\omega \mathrm{t}+\frac{2 \pi}{3}\right)=\mathrm{v}_{\mathrm{b}}(\omega \mathrm{t})
\end{aligned}
$$

\subsection{Odd symmetry}

If $v(\omega t)$ is a periodic function with symmetry, the following property of periodicity should be satisfied in Eq. (8):

$$
v(\omega t)=v(-\omega t)
$$

The Fourier coefficients are given in Eq. (9) for periodic functions with odd symmetry, 


$$
\begin{gathered}
a_{0}=0 \\
b_{n}=\frac{4}{\pi} \int_{0}^{\pi / 2} V_{d c} \sin (n \omega t) d(\omega t)
\end{gathered}
$$

A typical function with an odd symmetry is only written in reference to an infinite series of sine functions.

\subsection{Half wave symmetry}

Although 3PS focuses on eliminating triple harmonics, the half-wave symmetry eliminates even harmonics [13]. The removal of even harmonics is extremely important or otherwise leads to the resonance of electrical grids. In addition, the DC component is dangerous due to the shift of the point of operation of the electrical device. The waveform holds HWS if the image in the $\mathrm{x}$-axis shifted by half the time is close to itself. If the $v(t)$ function is a half-wave symmetry component and then satisfies the half-wave symmetry equation.

$$
v(\omega t)=-v(\omega t+\pi)
$$

The Fourier coefficients are given in Eq. (11) for periodical function with half wave symmetry:

$$
\begin{gathered}
a_{0}=0 \\
a_{n}=0 \text { for' }^{\prime} \text { 'is even } \\
a_{n}=\frac{4}{\pi} \int_{0}^{\pi / 2} V_{d c} \cos (n \omega t) d(\omega t), \text { for }^{\prime} n^{\prime} \text { is odd } \\
b_{n}=\frac{4}{\pi} \int_{0}^{\pi / 2} b_{n}=0 \text { for' } n^{\prime} \text { is even } \sin (n \omega t) d(\omega t), \text { for }^{\prime} n^{\prime} \text { is odd }
\end{gathered}
$$

\subsection{Quarter wave symmetry}

Quarter wave symmetry, a HWS subset, implies that not only all harmonics zero, but all harmonics are either in or opposite phase of a fundamental component. Since there are just two-phase angles $\left(0^{\circ}\right.$ and $\left.180^{\circ}\right)$ in a waveform of such symmetry, eliminating harmonics by injection needs little focus. QWS is achieved in combination of positive and negative half-cycles at midpoints [10]. It means that the waveform repeated the same sequence in each quarter of a cycle. The function of this waveform is represented in the Eq. (12).

$$
V(\omega t)=\left\{\begin{array}{cl}
v(\omega t) ; & 0 \leq \omega t \leq \frac{\pi}{2} \\
v(-\omega t+\pi) ; & \frac{\pi}{2} \leq \omega t \leq \pi \\
-v(\omega t+\pi) ; & \pi \leq \omega t \leq \frac{3 \pi}{2} \\
-v(-\omega t+\pi) ; & \frac{3 \pi}{2} \leq \omega t \leq 2 \pi
\end{array}\right.
$$

If $\mathrm{v}(\mathrm{t})$ is half-wave symmetry and periodic function, then it is called odd quarter-wave symmetry. The Fourier coefficients are given by Eq. (13) for periodical functions with an odd quarter wave symmetry.

$$
\begin{gathered}
a_{0}=0 \\
a_{n}=0 \text { for all 'n' } \\
b_{n}=0 \text { for' }^{\prime}{ }^{\prime} \text { is even } \\
b_{n}=\frac{4}{\pi} \int_{0}^{\pi / 2} V_{d c} \sin (n \omega t) d(\omega t), \text { for }^{\prime} n^{\prime} \text { is odd }
\end{gathered}
$$

A periodic function with an odd wave symmetry for a quarter has an average zero value. The explanation is that the functionality is odd and often means that all cosine harmonics are zero. Since of the waveform's half-wave symmetry, all coefficients of $a_{n}$ and even numbered $b_{n}$ are zero. When the corresponding bn coefficient equals zero, the nth harmonic is removed. Triplen harmonics are often cancelled out in line voltage for a three-phase system and are thus not relevant. The lower order harmonics to be eliminated are therefore odd components specified as 5, 7, 11, 13, 17 ..., SHE-PWM was specifically introduced for 2-level (bipolar) and 3-level (unipolar) converters, and the related waveforms of operation are described following.

\subsection{Unipolar switching scheme for SHE-PWM}

For unipolar switching in SHE-PWM, the output levels are $+\mathrm{V}_{\mathrm{dc}},-\mathrm{V}_{\mathrm{dc}}$ and 0 . The below Figure 1 illustrates the unipolar switching scheme of SHE-PWM for 3 switching angles. The unipolar SHE-PWM utilizing fixed switching angles to produce output having many pulses of different widths are addressed by Namboodiri et al. [22, 23]. The total number of pulses per cycle is twice that of switching angles in the switching sequence.

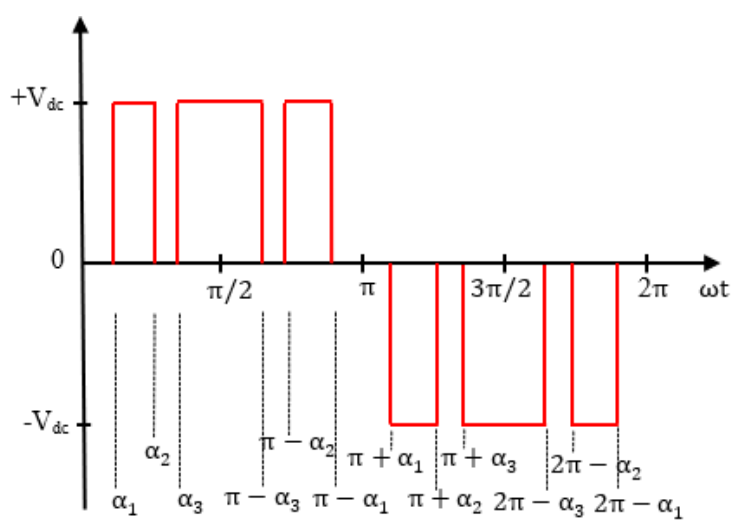

Figure 1. Unipolar PWM switching scheme

Mathematical models of unipolar programmed SHE-PWM output waveform for the three-level output is derived from the Fourier expansion as:

$$
\begin{gathered}
V(\omega t)=\sum_{n=1}^{\infty} b_{n} \sin (n \omega t) \\
b_{n}=\frac{4}{\pi} \int_{0}^{\pi / 2} V_{d c} \sin (n \omega t) d(\omega t) \text { for } n \text { is odd } \\
a_{n}=0 \text { for all' } n^{\prime}
\end{gathered}
$$

Waveform approximation with $\mathrm{N}$ number of switching angles per cycle for Fourier coefficients is given in Eq. (14). 


$$
\begin{gathered}
\mathrm{a}_{\mathrm{n}}=0 \\
\mathrm{~b}_{\mathrm{n}}=\frac{4 \mathrm{~V}_{\mathrm{dc}}}{\mathrm{n} \pi} \sum_{\mathrm{i}=1}^{\mathrm{N}}(-1)^{\mathrm{i}+1} \cos \left(\mathrm{n} \alpha_{\mathrm{i}}\right)
\end{gathered}
$$

Eq. (15) contains non-zero coefficients of $b_{n}$ for ' $n$ ' is odd.

$$
\mathrm{b}_{\mathrm{n}}=\frac{4 \mathrm{~V}_{\mathrm{dc}}}{\mathrm{n} \pi}\left(\cos n \alpha_{1}-\cos n \alpha_{2}+\cos n \alpha_{3} \ldots\right)
$$

Fourier expansion and its simplified form are now described in Eqns. (16) \& (17) respectively.

$$
\begin{gathered}
\mathrm{V}(\omega \mathrm{t})=\frac{4 \mathrm{~V}_{\mathrm{dc}}}{\pi}\left\{\left(\cos \alpha_{1}-\cos \alpha_{2}+\cos n \alpha_{3}\right.\right. \\
-\cdots) \sin \omega \\
+\left(\cos 3 \alpha_{1}-\cos 3 \alpha_{2}\right. \\
\left.+\cos 3 \alpha_{3} \ldots\right) \frac{\sin 3 \omega \mathrm{t}}{3} \\
+\left(\cos 5 \alpha_{1}-\cos 5 \alpha_{2}\right. \\
\left.\left.+\cos 5 \alpha_{3} \ldots\right) \frac{\sin 5 \omega \mathrm{t}}{5}+\cdots\right\} \\
\mathrm{V}(\omega \mathrm{t})=\frac{4 \mathrm{~V}_{\mathrm{dc}}}{\pi}\left\{\sum_{n=1,3, \ldots}^{\infty} \frac{\operatorname{sinn} \omega \mathrm{t}}{\mathrm{n}}\left[\sum_{\mathrm{i}=1}^{\mathrm{N}}(-1)^{\mathrm{i}+1} \cos n \alpha_{\mathrm{i}}\right]\right\}
\end{gathered}
$$

The above equation will fulfil the preceding constraint,

$$
\alpha_{1}<\alpha_{2}<\alpha_{3}<\cdots \ldots \ldots<\alpha_{N}<\frac{\pi}{2}
$$

Figure 1 is described for three switching angles $\alpha_{1}, \alpha_{2}, \alpha_{3}$ per each quarter cycle, therefore three number of equations to be formulated using Fourier series method. Among these three equations, one must be equated to the fundamental component of voltage utilized and the remaining two equations are to be equated to lowest harmonics to be eliminate (here, $5^{\text {th }} \& 7^{\text {th }}$ ). Thee three non-linear expressions is given below.

$$
\left.\begin{array}{c}
\frac{4 \mathrm{~V}_{\mathrm{dc}}}{\pi}\left(\cos \alpha_{1}-\cos \alpha_{2}+\cos n \alpha_{3}\right)=\mathrm{V}_{1} \\
\left(\cos 5 \alpha_{1}-\cos 5 \alpha_{2}+\cos 5 \alpha_{3}\right)=0 \\
\left(\cos 7 \alpha_{1}-\cos 7 \alpha_{2}+\cos 7 \alpha_{3}\right)=0
\end{array}\right\}
$$

Because of the three-phase balanced circuit properties, the harmonics in 3-phase systems, whose order is multiple of three, will be cancelled. The mathematical models of single and three phase systems are the same because triple harmonics are sometimes ignored in 3-phase implementation.

A significant portion of the bipolar SHE-PWM supports Unipolar SHE-PWM. Despite low modulation indexes, Unipolar SHE-PWM is still in operation. Like for bipolar SHE PWM, harmonic distortion is one of the drawbacks of unipolar SHE PWM. Unipolar SHE-PWM offers strong THD production for weak modulation indexes. Yet unipolar switching modulation contains less THD than bipolar switching modulation referred to SHE-PWM. This gives a more natural approximation of the sinusoidal waveform. The unipolar switching is therefore more likely than the bipolar SHE-PWM to contain less EMI. Bipolar SHE-PWM cause voltage differences equivalent to $2 \mathrm{Vdc}$. Unipolar SHEPWM can, however, produce voltage changes equivalent to Vdc. However, the unipolar SHEPWM raises the active switching frequency by a little value than the bipolar SHE-PWM.

\subsection{Bipolar switching scheme for SHE-PWM}

Bipolar switching is another scheme of SHE-PWM to remove the specific harmonics in the converter output [22-24]. Bipolar SHE-PWM has been widely used for many years for switching schemes requiring harmonic elimination. The line to neural voltage is $+\mathrm{Vdc}$ or $-\mathrm{Vdc}$ for the bipolar SHE-PWM. The bipolar designed PWM models have a single phase (SLN1: QWS PWM, $0^{\circ}$ to $90^{\circ}$ angle spreading, and SLN 2: same with the phase shift as the SLN1) and implementations in three phases (TLN1: QWS PWM, $0^{\circ}-90^{\circ}$ and TLN2: quarter wave symmetry $\mathrm{PWM}, 0^{\circ}-60^{\circ}$ switching angle). The TLN1 switching scheme is implemented in Figure 2 considering three switching angles. The main reason for choosing this form of TLN1 SHE-PWM leads to reduce harmonic losses and hence reduces the $\mathrm{AC}$ motor drive's harmonic heating.

TLN1 waveform is considered with quarter wave symmetry with phase spread of $0^{\circ}$ to $90^{\circ}$ for calculation of switching angles. Eq. (19) describes the mathematical formulation of Fourier series for single phase output waveform.

$$
\begin{gathered}
v(\omega t)=\sum_{n=1}^{\infty} b_{n} \sin (n \omega t) \\
a_{n}=0 \text { for all' } n^{\prime} \\
b_{n}=\frac{4}{\pi} \int_{0}^{\pi / 2} V_{d c} \sin (n \omega t) d(\omega t) \quad \text { for } n \text { is odd }
\end{gathered}
$$

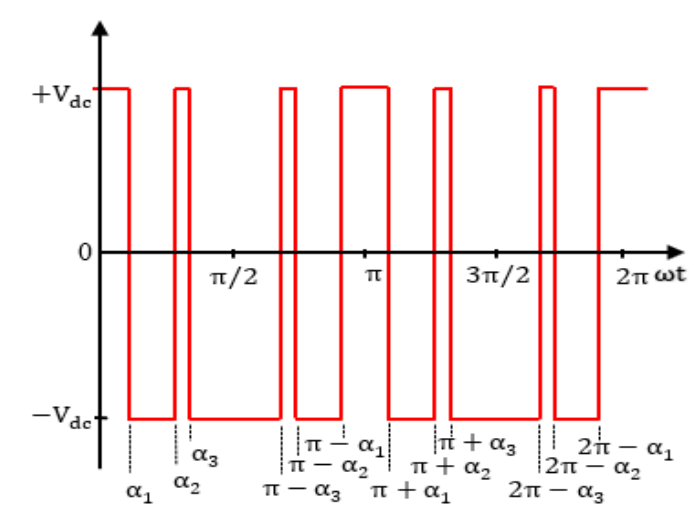

Figure 2. Bipolar PWM switching scheme

The Fourier series expansion is given Eq. (20) for $\mathrm{N}$ number of switching angles,

$$
\begin{gathered}
a_{n}=0 \text {, for all ' } n \text { ' } \\
b_{n}=\frac{4 V_{d c}}{n \pi}\left[-1-2 \sum_{i=1}^{N}(-1)^{i} \cos \left(n \alpha_{i}\right)\right]
\end{gathered}
$$

The non-zero coefficients of $b_{n}$ is obtained from the Eq. (21).

$b_{n}=\frac{4 V_{d c}}{n \pi}\left(-1+2 \cos n \alpha_{1}-2 \cos n \alpha_{2}+2 \cos n \alpha_{3}-\cdots\right)$

Fourier series expansion and its summarized form is represented in Eqns. (22) \& (23) respectively. 


$$
\begin{aligned}
& \mathrm{V}(\omega \mathrm{t})=\frac{4 \mathrm{~V}_{\mathrm{dc}}}{\pi}\left\{\left(-1+2 \cos \alpha_{1}-2 \cos \alpha_{2}+2 \cos n \alpha_{3}\right.\right. \\
& -\cdots) \sin \omega t \\
& +\left(-1+2 \cos 3 \alpha_{1}-2 \cos 3 \alpha_{2}\right. \\
& \left.+2 \cos 3 \alpha_{3}-\cdots\right) \frac{\sin 3 \omega \mathrm{t}}{3} \\
& +\left(-1+2 \cos 5 \alpha_{1}-2 \cos 5 \alpha_{2}\right. \\
& \left.\left.+2 \cos 5 \alpha_{3}-\cdots\right) \frac{\sin 5 \omega t}{5}+\cdots\right\} \\
& V(\omega t)=\frac{4 V_{d c}}{\pi}\left\{\sum_{n=1,3, \ldots}^{\infty} \frac{\operatorname{sinn} \omega t}{n}[-1\right. \\
& \left.\left.-2 \sum_{\mathrm{i}=1}^{\mathrm{N}}(-1)^{\mathrm{i}} \cos n \alpha_{\mathrm{i}}\right]\right\}
\end{aligned}
$$

The above equation should satisfy the following constraint,

$$
\alpha_{1}<\alpha_{2}<\alpha_{3}<\cdots \ldots \ldots . \alpha_{N}<\frac{\pi}{2}
$$

Figure 2 is described for three switching angles $\alpha_{1}, \alpha_{2}, \alpha_{3}$ per each quarter cycle, therefore three number of equations to be formulated using Fourier series method. Among these three equations one must be equated to the fundamental component of voltage utilized and the remaining two equations are to be equated to lowest harmonics to be eliminate (here, $5^{\text {th }} \& 7^{\text {th }}$ ).

$$
\left.\begin{array}{r}
\frac{4 \mathrm{~V}_{\mathrm{dc}}}{\pi}\left(-1+2 \cos \alpha_{1}-2 \cos \alpha_{2}+2 \cos n \alpha_{3}\right)=\mathrm{V}_{1} \\
-1+2 \cos 5 \alpha_{1}-2 \cos 5 \alpha_{2}+2 \cos 5 \alpha_{3}=0 \\
-1+2 \cos 7 \alpha_{1}-2 \cos 7 \alpha_{2}+2 \cos 7 \alpha_{3}=0
\end{array}\right\}
$$

Bipolar SHE-PWM has the most significant benefit that the control is not as complex as other methods. The applicability of bipolar SHE-PWM where lower modulation indices have been used is one of the major issues. In utilizing tiny modulation indexes, the required harmonic elimination mechanism cannot be achieved using the simple switching scheme. Both methods are focused on the frequency domain relative to the time domain cantered PWM space vector and bipolar modulation. Thus, both the methods have substantially reduced harmonic output and are commonly advised from bottom to top modulation region. Usually, the 3-level inverter utilizes high voltages and uses the low-switching frequency GTO switches. The need to introduce an appropriate low- to large modulation strategy is clearly backed by this.

\subsection{SHE-PWM switching scheme for multilevel output}

In addition, with the above discussed two level and three level switching schemes, another switching scheme is employed for multilevel inverters to produce stepped wave output voltages [25]. The expansion technique of the Fourier series is used to evaluate the waveform of the inverter. Fourier's generalized expansion can be demonstrated as:

$$
V(\omega t)=\sum_{n=1}^{\infty} V_{n} \sin (n \omega t)
$$

where, $\mathrm{V}_{\mathrm{n}}=$ magnitude of $\mathrm{n}^{\text {th }}$ order harmonic and the switching angle is around $0^{\circ}$ and $90^{\circ}$ (i.e., $0<\alpha_{i}<\frac{\pi}{2}$ ). Owing to the odd symmetry of QWS, even-order harmonics are zero. Hence, the $\mathrm{V}_{\mathrm{n}}$ becomes,

$$
V_{n}=\left\{\begin{array}{c}
\frac{4 V_{d c}}{n \pi} \sum_{i=1}^{k} \cos \left(n \alpha_{i}\right) ; \text { for odd values of }{ }^{\prime} n^{\prime} \\
0 ; \text { for even values of } n^{\prime}
\end{array}\right.
$$

SHEPWM attempts to eliminate reduced-order harmonics while filters delete leftover harmonics. In this article a $(\mathrm{k}+1)$ level inverter waveform is chosen for eliminating the reduced order harmonics without loss of generality is presented in Figure 3. Therefore, four nonlinear equations with seven switching angles are required to satisfy specific harmonics to remove third, fifth, and seventh harmonics.

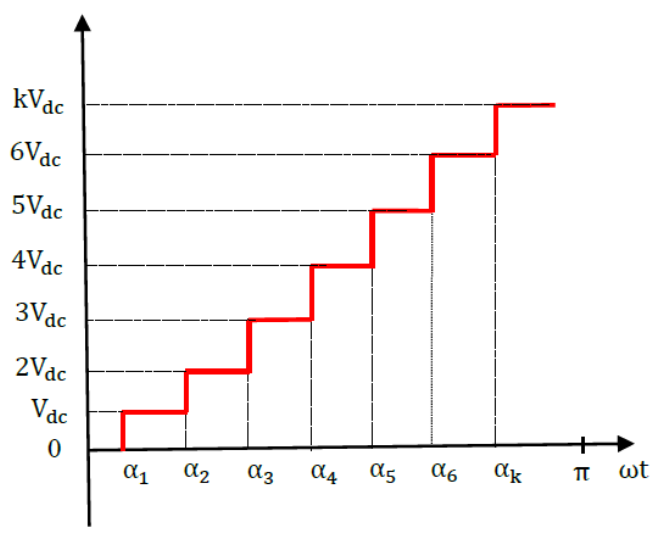

Figure 3. Stepped wave multi level output

$$
\left.\begin{array}{l}
\frac{4 \mathrm{~V}_{\mathrm{dc}}}{\pi}\left[\cos \alpha_{1}+\cos \alpha_{2}+\cdots+\cos \alpha_{k}\right]=\mathrm{V}_{1} \\
\frac{4 \mathrm{~V}_{\mathrm{dc}}}{3 \pi}\left[\cos 3 \alpha_{1}+\cos 3 \alpha_{2}+\cdots+\cos 3 \alpha_{\mathrm{k}}\right]=\mathrm{V}_{3} \\
\frac{4 \mathrm{~V}_{\mathrm{dc}}}{5 \pi}\left[\cos 5 \alpha_{1}+\cos 5 \alpha_{2}+\cdots+\cos 5 \alpha_{\mathrm{k}}\right]=\mathrm{V}_{5} \\
\frac{4 \mathrm{~V}_{\mathrm{dc}}}{7 \pi}\left[\cos 7 \alpha_{1}+\cos 7 \alpha_{2}+\cdots+\cos 7 \alpha_{\mathrm{k}}\right]=\mathrm{V}_{7}
\end{array}\right\}
$$

In Eq. (27), $V_{3}, V_{5}, V_{7}$ are equated to zero to eliminate the selective harmonics and the modulation index for fundamental voltage. Modulation index is given as,

$$
M=\frac{V_{1}}{V_{1 \max }}
$$

where,

$\mathrm{V}_{1 \text { max }}=$ maximum obtainable fundamental voltage;

$\mathrm{V}_{1 \max }=\frac{4 \mathrm{kV}_{\mathrm{dc}}}{\pi}$;

$\mathrm{V}_{1}=$ Actual fundamental voltage;

$\mathrm{k}=$ Degree of freedom $=(\mathrm{L}-1) / 2$;

$\mathrm{L}=$ Levels of output voltage.

The above conditions can be written by integrating the Eqns. (27) and (28) in the following manner. 


$$
\left.\begin{array}{c}
\frac{4 \mathrm{~V}_{\mathrm{dc}}}{\pi}\left[\cos \alpha_{1}+\cos \alpha_{2}+\cdots+\cos \alpha_{k}\right]=\mathrm{M} \\
\frac{4 \mathrm{~V}_{\mathrm{dc}}}{3 \pi}\left[\cos 3 \alpha_{1}+\cos 3 \alpha_{2}+\cdots+\cos 3 \alpha_{\mathrm{k}}\right]=0 \\
\frac{4 \mathrm{~V}_{\mathrm{dc}}}{5 \pi}\left[\cos 5 \alpha_{1}+\cos 5 \alpha_{2}+\cdots+\cos 5 \alpha_{\mathrm{k}}\right]=0 \\
\frac{4 \mathrm{~V}_{\mathrm{dc}}}{7 \pi}\left[\cos 7 \alpha_{1}+\cos 7 \alpha_{2}+\cdots+\cos 7 \alpha_{\mathrm{k}}\right]=0
\end{array}\right\}
$$

The switching angles must not violate the constraints,

$$
\alpha_{1}<\alpha_{2}<\alpha_{3}<\alpha_{4}<\ldots<\alpha_{k}<\frac{\pi}{2}
$$

Solution of the following series of Eq. (29), meeting the restriction (30) the inverter switching angle can be obtained. Thus SHE-PWM gives the feasible operation to the multilevel inverter by eliminating the lower order harmonics at fundamental frequency.

\section{SOLUTION METHODS TO SHEPWM}

Researchers have made considerable efforts in recent times in designing and refining various algorithms and solution methods to achieve optimal and/or different solutions with a broad variety of SHE-PWM formulations. This segment discusses the state-of-the-art of some methodologies (as listed in Figure 4), their functionalities and effects.

\subsection{Numerical methods}

Initial solutions to solving the equation structure is based on iterative computational techniques such as Newton - Raphson method. Newton-Raphson (NR) algorithm is the most employed iterative computational approach to solve the SHE problem as it has quicker quadratic root convergence and more simplicity to use with larger number of variables [26, 27]. A significant aspect of such strategies is that convergence relies strongly on accurate prediction of initial values, and though these initial values can be estimated for simple waveforms with limited switching angles [28, 29], this might not be feasible with large angle waveforms or multilevel waveforms.

However, methods for calculating initial values, such as predictive algorithms, have been stated in the literature [29, $30]$, which compute the initial values and then use of a Newton algorithm in one or two iterations to achieve the same solution. The starting point was also initialized with an equal area algorithm [31, 32]. The method Chebyshev [25] has been used for algebraical transformation of SHE's trigonometric equation, enabling strong convergence and a reduction in processing time. The phase-shift technique offers a starting point for a non-constrained optimization method [33]. This research suggests even a harmonic mirror surplus approach in order to reduce the computational burden of the five-level inverter harmonic suppression.

\subsection{Multiple solution algorithms}

The methods described numerical methods having different variations, despite that they had one major drawback is that they ignore (cannot find) the multiple solutions of the SHE problem. In order to ensure consistency and find all solutions, transformation measures into non-linear equations have been researched extensively. To transform such equations into linear algebraic equations, which can be quickly solved by reducing the computational time, a two-level [34, 35] and multi-level waveform analysis [36] centred on the Walsh functions have been implemented. The harmonic amplitudes are specifically articulated in conjunction with switching angles, such that a straight-line curve fitting model enables automated application. All potential switching strategies are sought for the global solution, so the correct initial requirements are necessary for the ideal solution to be assured. Each solution is limited by only one angle within a specified interval [37]. If a solution needs two angles, the solution would not be found at the same interval. Consequently, this method's precision is a factor in the PWM signal sampling points (i.e. the range of intervals), which furthermore increases statistical complexity if greater precision is required. A pulse blocking feature has been used to mitigate this condition, such that more than one angle will differ in a chosen interval [38]. However, an effective conversion algorithm between the Fourier series and the Walsh series is considered necessary [35].

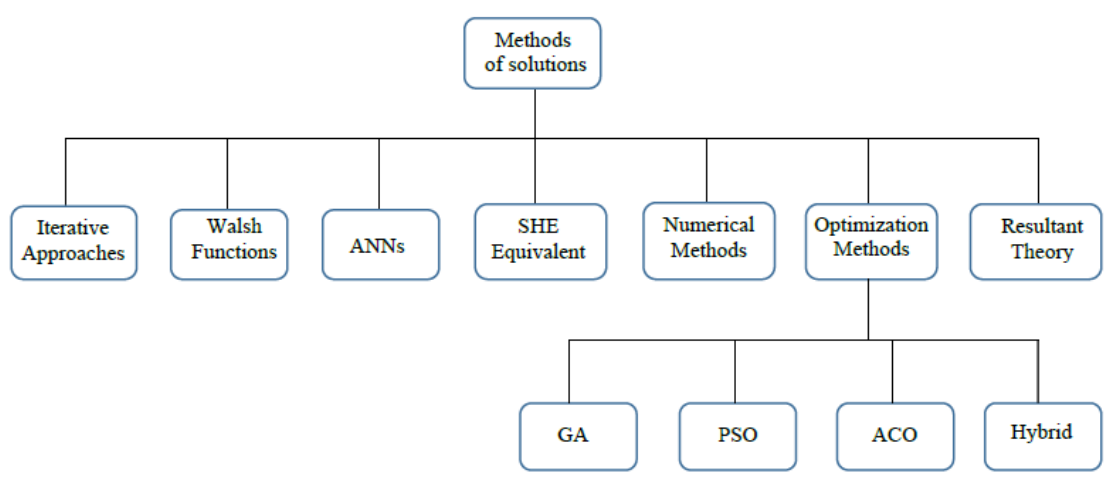

Figure 4. SHE-PWM solving techniques and algorithms

\subsection{Resultant theory method}

The transcendental equations of SHEPWM are developed and evaluated to analogous polynomial equations for two-level and multilevel waveforms utilizing trigonometric identities $[39,40]$. Eq. (2) shall be transformed into an analogous polynomial, assuming that $\mathrm{x}_{1}=\cos \left(\alpha_{1}\right), \mathrm{x}_{2}=$ $\cos \left(\alpha_{2}\right), \ldots \ldots, x_{i}=\cos \left(\alpha_{i}\right)$. The resultant theory is then utilized to measure the corresponding polynomial equation and obtain all the switching angle solution sets for the required SHE-PWM waveform [39-41]. Therefore, symmetric [42, 43] or power sums [44] minimize computational burden, reducing 
the degree of polynomial equations. The resultant theory's key drawbacks are:

1) Polynomial order is increased with the number of harmonics to be eliminated; therefore, even though the harmonics which may be eliminated are low, they can easily be extended.

2) When there are several dc sources, the polynomial degrees are very broad, and the resultant polynomials have a very heavy computational burden [42].

\subsection{Optimization algorithms}

There are vast number of optimization algorithms implemented for SHE optimization problem, the most popular algorithms are given in this literature. The SHE-PWM can be rephrased into an optimisation problem when trigonometric equations for any harmonic as described in (2) are expressed in the cost function. With the restriction placed by (4), the cost function is reduced, and advanced stochastic analysis approaches are utilized to locate all possible sets of solutions. Transcendental SHE-PWM equations will be transformed into constraint optimisation problems [44-47] and the optimum switching angle will then be calculated by a DE algorithm. Another approach based on a minimization technique and a random search is initially extended to two- and three-level waveforms [48, 49] and then generalized to different multilevel waveforms [50-57]. The approach is used to generate all solutions for a SHE problem directly in the series of transcendental equations, even though several harmonics are removed. The method is straightforward.

Genetic algorithms (GAs) have helped to resolve the SHEPWM problem in a vast number of research study papers [49, 58-60]. The GAs was first used as a method of optimizing switch angles by decreasing line current harmonics in a PWM dc-ac inverter [61], they were later implemented in the selected harmonic elimination or THD minimization (i.e., in two, three, and multilevel inverters). PSO is another successful method of optimizing the SHE-PWM problem recently applied to different waveforms [62-64]. This is similar to the GA (population-based searching strategy) approach in which a populace of arbitrary services at first provided to the machine is a PSO that has no "mutation," "recombination" or "survival of the fittest" operators. Fragments observe individuals traveling around multi-dimensional space. For each bit, the most effective position is acquired with the suitable remedy (fitness) to itself as well as its neighbours. As said, this formula's process starts with a first position as well as speed for every particle, for which the velocities are bound due to non-flying in pointless areas and likewise overrunning prohibitions.

Ant swarm optimization (ACO) another optimizing method of the SHE-PWM problem to offer an optimization solution in ant nest optimization (ACO), which originally uses ant populace $[65,66]$. The ant colony's job is to pass across the neighbouring states of the problem by introducing an efficient controller (plan) for stochastic local judgment, which induces the operation's optimization query. Other procedures at ACO are pheromone trail dissipation as well as daemon activities. Using ACO to discover good paths via chart will could computationally issues. The initial search as a graph academic method related to the construction of a measuring tree to analyse the observability of the network. Whale optimization algorithm was proposed in 2016 using a modern population dependent algorithm to the SHE problem optimization [67].
The algorithm simulates the humpback whales' social behaviour. Like other population-based algorithms, WOA uses several random candidate solutions (population) and applies three rules to update and enhance the positioning of candidate solutions at each stage, which are prey-encircling, spiral-upgrading, and prey-searching. WOA proved one of the common techniques of optimisation in terms of inverter efficiency, convergence, and computational overhead.

\section{IMPLEMENTATION OF SHEPWM ON MULTILEVEL CONVERTERS}

The solutions of MSHE-PWM equations as defined in Section-2 are completely different from the converter topology and only rely on voltage levels and switching angles, based on the algorithms mentioned in Section-3. Nonetheless, each converter has its own operating specifications which needs specific implementation to generate the necessary waveform at the power circuit terminals. This segment discusses the main features of applying MSHE-PWM in multilevel conversion configurations.

\subsection{CHB and hybrid MLIs}

MSHE-PWM design is the simplest, with various implementations [68-71] for CHB converters and hybrid converters. The balance on either side of the bridges is dependent on certain parameters including the balance of the dc link voltages and/or the loss of equalization. The bridge may be modified from one point of view to another. Figure 5(a) demonstrates a five-level CHB converter angle distribution illustration between two H-bridges. The switching angles are distributed randomly in arbitrary manner or based on level shifted carriers Figure 5(b) [72] or phase shifted carriers Figure 5(c) [73].

Multi-level CHB and hybrid converters may be worked at different or varying voltage levels [74], which implies that there is more flexibility to choose bridges for each transition. However, the bridge angle distribution in Hybrid converters considers flying capacitor voltage standard [53] and its reference value differences in voltage. and the voltage deviation from its reference value. A system for the equalization of minor differences in dc-voltages for cascaded H-bridge converters was described in the papers $[75,76]$.

\subsection{NPC and FC converters}

NPC and FC 3-level converters require a voltage balance of the capacitor (both dc-link and FC). The voltage balance of a dc-link condenser is accomplished with the passive selfbalancing functionality of the topology with a larger time constant. Active methods focused on selecting redundant switching states are necessary for accelerated convergence [50]. Effective redundant status selection is also essential for FC converters. Further changes to the properties of the voltage equilibrium can be obtained by applying a small variance $(\epsilon)$ to the pre-determined switching angles (Figure 6) by either increasing or reducing the conduction period in each capacitor according to the voltage variability and current path.

$$
\alpha_{i}^{\prime}=\alpha_{i} \mp \varepsilon
$$

The conductive time variations help to match the condenser voltage with fixed reference value. Transition duration is often 
changed, so this can have a nondetrimental impact on harmonic output. However, the distortions induced by the unbalanced capacitor voltages seen in the papers $[50,51]$ is negligible, which is not relevant. The technique refers similarly to NPC converters and active NPC converters (ANPC) [50, 51] and the Fc topologies [77, 78]. Figure 6(b) shows the key principle behind this process.

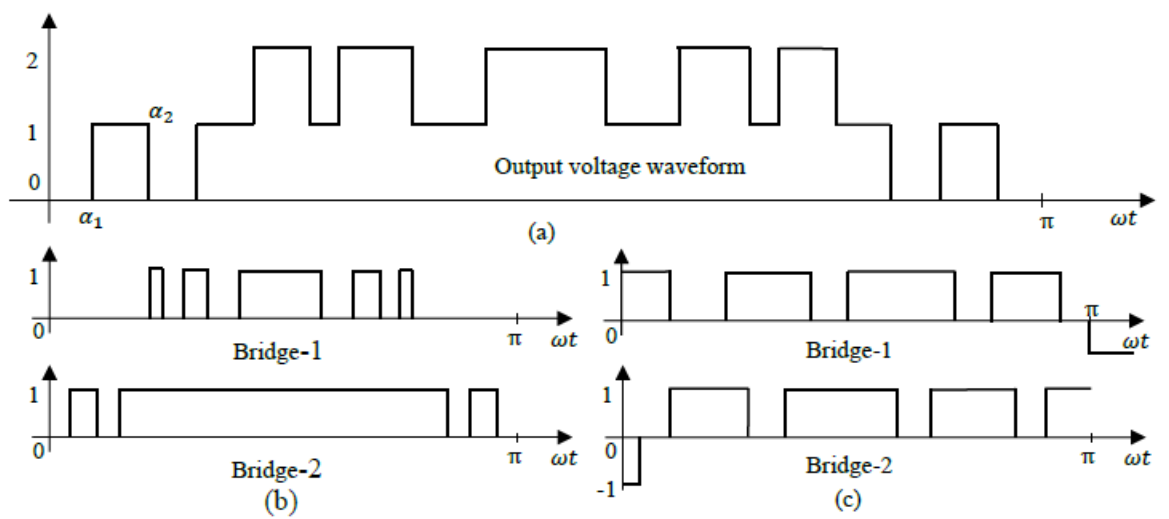

Figure 5. Multilevel output and angle delivery. (a) 5-level output waveform, (b) LSC-PWM output counterpart and (c) PSCPWM output counterpart

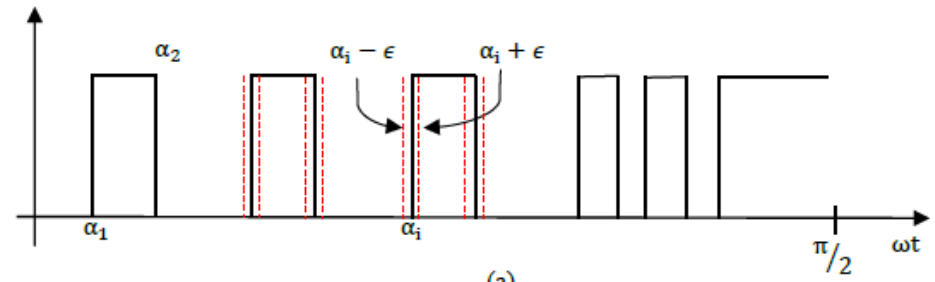

(a)

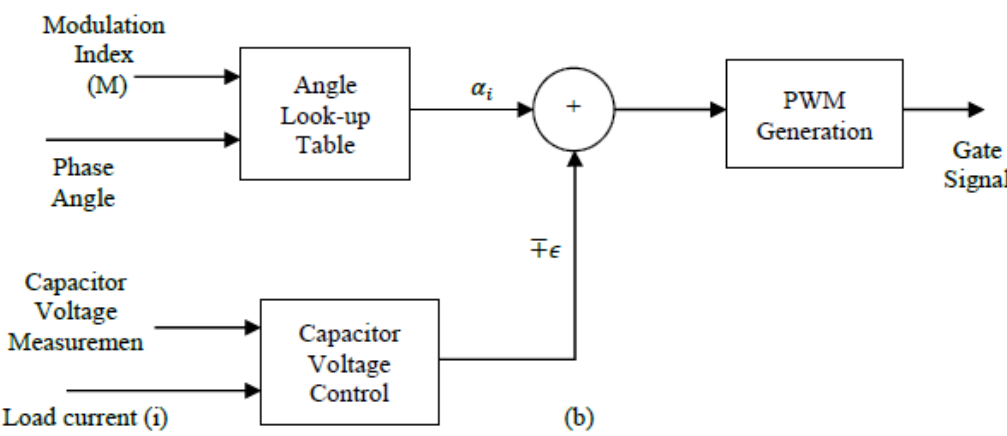

Figure 6. Significant differences in the switching angles allow NPC, ANPC and FC voltage balance.

(a) Modification of voltage waveform and switching angle, and (b) Angle variance estimation $\varepsilon$ and generation of PWM

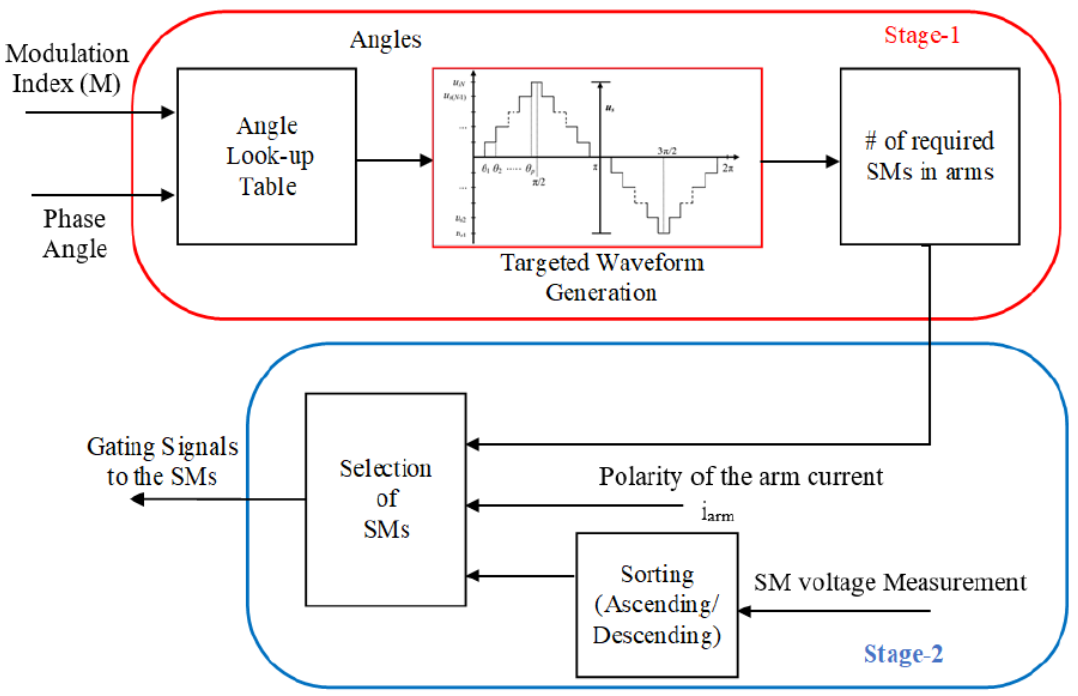

Figure 7. A 2-stage modulation and deployment of SHE-PWM for MMC 


\subsection{Multi-module converters}

A multi-module converter [79] uses a 3-phase, 2-level interface, and a plugin multi-winding transformer in the system output. The purpose of the two-level angle distribution of each module is the difference of increasing dc-link when the average dc-link voltage is regulated. The single step switching patterns of each module [54] from the optimized multi-level waveform can be pre-selected and the generated patterns can be rotated to provide the consistency required. In a multimodule converter, the dc-link condensers are not completely powered, so the variation on the actual dc-link condensers is slightly lower than the condenser voltage from which the converter is supplied. Pattern repetition may be introduced over a span of time instead of any turn-around moment, so that the converter modules' switching frequency or related switching losses are not increased aggressively.

\subsection{Modular multilevel converters}

MMCs are the most powerful topology converter in multilevel processing. A special characteristic of PWM in MMCs is that it is usually performed by an SM condensing voltage balancing method, which is not specifically associated to the changeover of a common submodule (SM) [55, 56]. SHEPWM multilevel methods may be applied explicitly as long as the needs of the MMC SMs for capacitor voltage control have been addressed.

The modulation is separated into two distinct stages by standard PWM implementations for MMC. The first stage utilizes pre-calculated switching angles, an input from external controls to evaluate the waveform of a multiple level and the number of sub-modules attached to each step-leg's top and bottom arm. Depending on the method, such trends can be of fundamental frequency $[80,81]$ or higher $[55,56]$. Centred on an algorithm of voltage sorting and balancing of the submodule condenser, the second stage specifies the submodules that are linked or bypassed in the converter arms and produces the signals. Figure 7 illustrates the two-stage MMC algorithm.

In addition, a selection may be rendered dependent on the energy estimate $[80,81]$ of each SM condenser using standard frequency modulation. Selection is made simpler by knowing the exact transition positions and voltage balance by integrating accumulated energy in and out of SMs to zero for many cycles. MMCs normally operate at high voltage at low frequencies; SHE-PWM's advantages can be limited in such environments. However, MMC modulation strategies persist in intensive research $[55,56,80,81]$.

\section{KEY APPLICATIONS}

Switching losses are of great concern in medium- and highpower converters and their elimination is of key importance. In contrast with carrier-based PWM strategies, SHE-PWM gives a substantially reduced equal level of switchable power losses and strong harmonics.

It makes it a viable and appealing approach for such uses, including grid assistance and grid linked converters. Throughout this segment one can study and outline some existing applications that use SHE-PWM as a function of modulation.

\subsection{Motor drive converter control with SHEPWM}

While SHE-PWM could have been challenging to incorporate online, many research papers have shown the feasibility of utilizing its functionality in motor drives (i.e. medium voltage and high power). The solution eliminates harmonic disturbances at low order on both the line and the motor sides, thereby reducing the losses of switching and increasing the power factor. HE-PWM was used to remove low order harmonic voltage from a PMSM [82], which results in the removal of current harmonics. SHE-PWM attempted to claim that it may be ideal for applications of motor drive systems such as pumps and fans that do not require strong dynamics due to the issue of switching patterns [79].

SHEPWM supported the installation of an ICGT-based $6 \mathrm{kV} / 1800 \mathrm{kVA}$ NPC converter motor [81]. The study shown that the SVM methodology is outperformed in terms of device output and thermal loss reduction with the same switching frequency [82]. For high-power back-to-back CSC drive systems, a high-power factor was suggested in the case of high-speed operation by low frequency switching equipment, with trapezoidal modulation [83] and SVM [84] modulation. In addition, the operation of the MSHE-PWM hybrid multilevel converter was analysed [85]. Often used as an acoustic noise reduction [86] and in common mode [49], MSHE-PWM was used in VSC-based drive applications. Recently a condenser less AC-AC motor drive was built with SHE-PWM to avoid the energy from being fed to the motor by low-order harmonics [86].

\subsection{Active power converters with SHEPWM}

Recently, SHE-PWM has also developed to provide low and high-power active rectifiers $[18,20]$. The SHE-PWM solution lowered substantially the existing THD of the three-level acdc converter $[18,19]$. The approach was further able, by means of the low frequency modulatory device, to regulate the voltage of the different cells of the cascaded multilevel active rectifiers [87, 88] and the current source rectifier [64]. The approach is employed to eliminate or reduce the need to filter harmonics in the 12-pulse active front end converter in compliance with IEEE Norm 519-1992 [57]. In addition, the SHE-PWM are found to boost the harmonic profile of the input current in an interleaved 4-quadrant traction rectifier [58-59].

\subsection{Grid connected converters with SHEPWM}

VSCs in modern power networks are gradually substituted by traditional passive grid-based FACTS systems and filters. Conversion losses, connected directly to the high frequency PWM process, are one of VSC dependent high-power applications, such as FACTS and HVDC systems, which present some severe and most difficult problems. Because of its low switching frequency, SHEPWM proved an important modulation strategy for these converters. In the recent technological literature [42, 46, 84], a variety of SHE-PWMbased STATCOM systems have been suggested. Together with phase-shift control, SHE-PWM was employed to remove lower-order harmonics from both standard [42] and multilevel [88] voltages of the VSC-based STATCOM systems which lead to the compliance of the input current with IEEE Standard 519-1992 [31]. This has also been applied to a CSC for mine pellets [45] to obtain a unit power factor and a line current that 
satisfy all relevant standards. SHE-PWM helped to eradicate the existing harmonics of a transformer-based large-power FACTS device [46] (i.e., $12 \mathrm{f} \pm 1$, where $\mathrm{f}$ is the basic frequency).

In addition, important research has also been recorded recently [88] where SHE-PWM has been integrated into multimodule HVDC transmission systems utilizing seriescontained two-level three-stage transmission systems. This offered wider harmonic bandwidth at reduced frequencies and decreases both the losses of switching and the criteria for filtering. SHE-PWM also provides the benefits of lower switching losses, improved DC connection pressures and stronger semiconductors for some grid-connected applications, such as PV grid interface systems [54, 62, 74]. SHE-PWM was recently reported on the use of multi-level converters to facilitate integration of distributed power resources, to compensate for harmonics from nonlinear loads [78].

\subsection{Other applications}

For various VSCs [61-64], SHE-PWM has been used to address the current zero-sequence problem. SHE-PWM removes the low-order harmonics on the waveform output voltage, particularly in the case of a multi-modular voltagesource inverter. The ZSCC in parallel multi-module converter with the selective removal of triple converter harmonics, or it reduces ZSCC by splitting the ZSCC direction [88]. The other fascinating feature is four-leg three-phase high or medium voltage inverters in which SHE-PWM reduces the zerosequence current again and allows the converter to work with low switching frequency, but still struggling with an unbalanced situation.

\section{CONCLUSIONS}

Selective harmonic elimination is really a successful modulation strategy for a wide range of low-switching frequency implementations, involving active regulation of harmonic spectrum and substantial reduction of switching frequency. A detailed analysis of the SHEPWM strategy design and study developments, based on multilevel waveforms and inverters (MSHE-PWM), were addressed in this article. The methods of solutions to the non-linear transcendental equations developed by the SHEPWM also presented. Among the existing solution methods, the optimization techniques with metaheuristic algorithms are more accurate for THD optimization and switching loss reduction. This study finally, suggest a multilevel inverter with SHEPWM controlled by optimization algorithms for better performance and improved efficiency.

Main findings of this study can be represented in:

a. The SHE-PWM waveform's structure and properties play significant role in deciding the nature of the problem, acquiring possible solutions and identifying solution. Number of switching angles and output voltage rates, among other significant considerations influencing equation analysis. Various symmetries may be applied, like QW, HW and non-symmetric waveforms, with QW providing easiest formulation and simpler extension to higher levels.

b. Widespread SHE-PWM formulation with a single equation will effectively promote the description of problems in all multilevel waveforms. By comparison with two-level structures, non-symmetric multilevel SHE-PWM becomes progressively complicated without any gain. The sophistication of the model becomes determined specifically by the criteria of symmetry.

c. The objective function is another important aspect and the removal of low-order harmonics may be relaxed to decrease THD or adhere to harmonic grid code restrictions. The necessity to remove or that the total number of harmonics expands the range of solutions accessible at the cost of low-order harmonics and the sub-optimal harmonic efficiency.

d. SHE-PWM determines the necessary waveform transitions. Moreover, application of the procedure relies on a multi-level converter topology and additional considerations should be addressed, such as equalization and distribution of the capacitor voltage.

SHE-PWM is hopefully a very optimistic solution to potential sophisticated power conversion systems and several work possibilities will be explored in many ways to optimize their characteristics practicality.

\section{REFERENCES}

[1] Ebadi, M., Joorabian, M., Moghani, J.S. (2014). Multilevel cascaded transformerless inverter for connecting distributed-generation sources to network. IET Power Electron, 7(7): 1691-1703. https://doi.org/10.1049/iet-pel.2013.0112

[2] Sajadi, R., Iman-Eini, H., Bakhshizadeh, M.K., Neyshabouri, Y., Farhangi, S. (2018). Selective harmonic elimination technique with control of capacitive DC-link voltages in an asymmetric cascaded $\mathrm{H}$-bridge inverter for STATCOM application. IEEE Transactions on Industrial Electronics, 65(11): 87888796. https://doi.org/10.1109/TIE.2018.2811365

[3] Lai, J.S., Peng, F.Z. (1996). Multilevel converters: a new breed of converters. IEEE Transactions on Industry Applications, 32(3): 509-517. https://doi.org/10.1109/28.502161

[4] Zhang, Y., Li, Y.W., Zargari, N.R., Cheng, Z. (2015). Improved selective harmonics elimination scheme with online harmonic compensation for high-power PWM converters. IEEE Trans. Power Electron, 30(7): 35083517. https://doi.org/10.1109/TPEL.2014.2345051

[5] Tripathi, A., Narayanan, G. (2014). High-performance off-line pulse width modulation without quarter wave symmetry for voltage source inverter. International Conference on Advances in Electronics Computers and Communications, IEEE, Bangalore, pp. 1-6. https://doi.org/10.1109/ICAECC.2014.7002464

[6] Moeini, A., Zhao, H., Wang, S. (2016). A currentreference-based selective harmonic current mitigation PWM technique to improve the performance of cascaded $\mathrm{H}$-bridge multilevel active rectifiers. IEEE Transactions on Industrial Electronics, 65(1): 727-737. https://doi.org/10.1109/TIE.2016.2630664

[7] Yang, K.H., Yuan, Z.B, Yuan, R.Y., Yu, W.S., Yuan, J.X., Wang, J. (2015). A Groebner bases theory-based method for selective harmonic elimination. IEEE Transactions on Power Electronics, 30(12): 6581-6592. 
https://doi.org/10.1109/TPEL.2014.2388077

[8] Enjeti, P.N., Ziogas, P.D., Lindsay, J.F., Rashid, M.H. (1990). A new PWM speed control system for high performance AC motor drives. IEEE Transactions on Industrial Electronics, 37(2): 143-151. https://doi.org/10.1109/41.52963

[9] Konstantinou, G.S, Agelidis, V.G. (2010). Bipolar switching waveform: Novel solution sets to the selective harmonic elimination problem. In Proceedings of IEEE ICIT, pp. 696-701. https://doi.org/10.1109/ICIT.2010.5472718

[10] Kulkarni, A., John, V. (2013). Mitigation of lower order harmonics in a grid-connected single-phase PV inverter. IEEE Transactions on Power Electronics, 28(11): 50245037. https://doi.org/10.1109/TPEL.2013.2238557

[11] Kamani, P.L., Mulla, M.A. (2018). Middle-level SHE pulse-amplitude modulation for cascaded multilevel inverters. IEEE Transactions on Industrial Electronics, 65(3):

2828-2833. https://doi.org/10.1109/TIE.2017.2742990

[12] Fei, W., Du, X., Wu, B. (2010). A generalized half-wave symmetry SHE-PWM formulation for multilevel voltage inverters. IEEE Transactions on Industrial Electronics, 57(9):

3030-3038 https://doi.org/10.1109/TIE.2009.2037647

[13] Dahidah, M.S.A., Agelidis, V.G. (2008). Selective harmonic elimination PWM control for cascaded multilevel voltage source converters: A generalized formula. IEEE Transactions on Power Electronics, 23(4): 1620-1630. https://doi.org/10.1109/TPEL.2008.925179

[14] Chiasson, J.N., Tolbert, L.M., McKenzie, K.J., Du, Z. (2003). Control of a multilevel converter using resultant theory. IEEE Transactions on Control Systems Technology, 63(3-5): 197-208. https://doi.org/10.1109/TCST.2003.810382

[15] Chiasson, J.N., Tolbert, L.M., McKenzie, K.J., Du, Z. (2005). Elimination of harmonics in a multilevel converter using the theory of symmetric polynomials and resultants. IEEE Transactions on Control Systems Technology, 13(2): 216-223. https://doi.org/10.1109/TCST.2004.839556

[16] Sun, J., Beineke, S., Grotstollen, H. (1996). Optimal PWM based on realtime solution of harmonic elimination equations. IEEE Transactions on Industrial Electronics, 11(4): https://doi.org/10.1109/63.506127

[17] Ozpineci, B., Tolbert, L.M., Chiasson, J.N. (2005). Harmonic optimization of multilevel converters using genetic algorithms. IEEE Power Electronics Letters, 3(3): 92-95. https://doi.org/10.1109/LPEL.2005.856713

[18] Lee, S.S., Chu, B., Idris, N.R.N., Goh, H.H., Heng, Y.E. (2016). Switched battery boost-multilevel inverter with GA optimized SHEPWM for standalone application. IEEE Transactions on Industrial Electronics, 63(4): 2133-2142. https://doi.org/10.1109/TIE.2015.2506626

[19] Taghizadeh, H., Hagh, M.T. (2010). Harmonic elimination of cascade multilevel inverters with nonequal DC sources using particle swarm optimization. IEEE Transactions on Industrial Electronics, 57(11): 36783684. https://doi.org/10.1109/TIE.2010.2041736

[20] Memon, M.A., Mekhilef, S., Mubin, M. (2018). Selective harmonic elimination in multilevel inverter using hybrid APSO algorithm. IET Power Electronics, 11(10): 1673-1680. https://doi.org/10.1049/iet- pel.2017.0486

[21] Namboodiri, A., Wani, H.S. (2014). Unipolar and bipolar PWM inverter. International Journal for Innovative Research in Science \& Technology, 1(7): 237-243. https://doi.org/10.1109/IJIRST.2014.2811275

[22] Lei, B., Xiao, G., Wu, X. (2013). Comparison of performance between bipolar and unipolar doublefrequency sinusoidal pulse width modulation in a digitally controlled $\mathrm{H}$-bridge inverter system. Chinese Physics B, 22(6). https://doi.org/10.1088/16741056/22/6/060509

[23] Addala, M., Pandu, K., Satyanarayna, V. (2015). A comparison analysis of unipolar and bipolar switching modulated cascade H-bridge multi level inverters. International Journal of Engineering Research and Applications, 5(1): 116-120. https://doaj.org/toc/22489622

[24] Dahidah, M.S.A., Agelidis, V.G. (2005). A hybrid genetic algorithm for selective harmonic elimination control of a multilevel inverter with non-equal DC sources. Proceedings of IEEE PEDS, pp. 1205-1210. https://doi.org/10.1109/PEDS.2005.1619871

[25] Lipo, T.A., Holmes, D.G. (2003). Pulse-Width Modulation for Power Converters: Principles and Practice. IEEE Press Series on Power Engineering. Wiley-IEEE Press.

[26] Enjeti, P.N., Ziogas, P.D., Lindsay, J.F. (1990). Programmed PWM techniques to eliminate harmonics: A critical evaluation. IEEE Transactions on Industrial Applications, 26(2): 302-316. https://doi.org/10.1109/28.54257

[27] Hamed, H.A., Al Mansoori, F.N., Bayoumi, E. (2019). A new approach to enhance the accuracy of selective harmonics-elimination technique for digital controllers. Journal of Electrical Engineering, 70(5): 358-369. https://doi.org/10.2478/jee-2019-0067

[28] Sun, J., Grotstollen, H. (1992). Solving nonlinear equations for selective harmonic eliminated PWM using predicted initial values. Proceedings of the International Conference on Industrial Electronics, Control, Instrumentation, and Automation, San Diego, CA, USA, 9(13): https://doi.org/10.1109/IECON.1992.254623

$259-264$

[29] Sun, J., Beineke, S., Grotstollen, H. (1996). Optimal PWM based on real-time solution of harmonic elimination equations. IEEE Transactions on Industrial Electronics, 11(2): 612-621. https://doi.org/10.1109/63.506127

[30] Chen, J.W., Liang, T.J., Wang, S.H. (2005). A novel design and implementation of programmed PWM to eliminated harmonics. Proceedings of IEEE IECON, Raleigh, NC, USA, 6(10): 1278-1283. https://doi.org/10.1109/IECON.2005.1569089

[31] Chen, J.W., Liang, T.J. (1997). A novel algorithm in solving nonlinear equations for programmed PWM inverter to eliminate harmonics. Proceedings of the IECON'97 23rd International Conference on Industrial Electronics, Control, and Instrumentation (Cat. No.97CH36066), New Orleans, LA, USA, 9(14): 698703. https://doi.org/10.1109/IECON.1997.671819

[32] Li, L., Czarkowski, D., Liu, Y., Pillay, P. (2000). Multilevel selective harmonic elimination PWM technique in series connected voltage inverters. IEEE Transactions on Industrial Applications, 36 (1): 160-170. 
https://doi.org/10.1109/28.821811

[33] Liang, T.J., O’Connell, R.M., Hoft, R.G. (1997). Inverter harmonic reduction using Walsh function harmonic elimination method. IEEE Transactions on Power Electronics, $12(6)$ : 971-982. https://doi.org/10.1109/63.641495

[34] Zheng, C., Zhang, B., Qiu, D. (2005). Solving switching angles for inverter's selected harmonic elimination technique with Walsh function. Proceedings of ICEMS, Nanjing, China, 2(29): 1366-1370. https://doi.org/10.1109/ICEMS.2005.202771

[35] Li, S., Ye, M. (2011). Simulation study of harmonic elimination technology for multi-level inverters. International Conference on Electronic and Mechanical Engineering and Information Technology, Harbin, Heilongjiang, China, pp. 12-14. https://doi.org/10.1109/EMEIT.2011.6023599

[36] Swift, F., Kamberis, A. (1993). A new Walsh domain technique of harmonic elimination and voltage control in pulse-width modulated inverters. IEEE Transactions on Power Electronics, 8(2): 170-185. https://doi.org/10.1109/63.223969

[37] Razzaghi, M., Nazarzadeh, J., Nikravesh, K.Y. (1998). A blockpulse domain technique of harmonics elimination in multilevel pulse-width modulated inverters. Electric Power Systems Research, 46(2): 77-81. https://doi.org/10.1016/S0378-7796(98)00027-3

[38] Chiasson, J.N., Tolbert, L.M., McKenzie, K.J., Du, Z. (2004). A complete solution to the harmonic elimination problem. IEEE Transactions Power Electronics, 19(1): 491-499. https://doi.org/10.1109/TPEL.2003.823207

[39] Chiasson, J.N., Tolbert, L.M., McKenzie, K.J., Du, Z. (2005). Elimination of harmonics in a multilevel converter using the theory of symmetric polynomials and resultants. IEEE Transactions on Control Systems Technology, 13(2): 216-223. https://doi.org/10.1109/TCST.2004.839556

[40] Tolbert, L.M., Chiasson, J.N., Du, Z., McKenzie, K.J. (2005). Elimination of harmonics in a multilevel converter with nonequal DC sources. IEEE Transactions on Industrial Applications, 41(1): 75-82. https://doi.org/10.1109/TIA.2004.841162

[41] Chiasson, J.N., Tolbert, L.M., Du, Z., McKenzie, K.J. (2005). The use of power sums to solve the harmonic elimination equations for multilevel converters. European Power Electronics and Drives Journal, 15(1): 19-27. https://doi.org/10.1080/09398368.2005.11463578

[42] Du, Z., Tolbert, L.M., Chiasson, J.N. (2006). Active harmonic elimination for multilevel converters. IEEE Transactions Power Electronics, 21(2): 459-469 https://doi.org/10.1109/TPEL.2005.869757

[43] Aziz, J.A., Salam, Z. (2004). A new pulse-width modulation (PWM) scheme for modular structured multilevel voltage source inverter. International Journal of $\quad$ Electronics, $91(4)$ : 211-226. https://doi.org/10.1080/00207210410001675644

[44] Agelidis, V.G., Balouktsis, A., Dahidah, M.S.A. (2008). A five-level symmetrically defined selective harmonic elimination PWM strategy: Analysis and experimental validation. IEEE Transactions on Power Electronics, 23(1):

19-26.

https://doi.org/10.1109/TPEL.2007.911770

[45] Rashid, M.I.M., Hiendro, A., Anwari, M. (2012).
Optimal HE-PWM inverter switching patterns using differential evolution algorithm. Proceedings of 2010 IEEE PECon., $\quad$ pp. 32-37. https://doi.org/10.1109/PECon.2012.6450232

[46] Azli, N.A., Yatim, A.H.M. (2000). Curve fitting technique for optimal pulse width modulation (PWM) online control of a voltage source inverter (VSI). Proceedings of IEEE-TENCON 2000, pp. 419-422. https://doi.org/10.1109/TENCON.2000.893701

[47] Konstantinou, G., Agelidis, V.G. (2010). Bipolar switching waveform: Novel solution sets to the selective harmonic elimination problem. Proceedings of IEEE ICIT, pp. 696-701. https://doi.org/10.1109/ICIT.2010.5472718

[48] Dahidah, M.S.A., Konstantinou, G., Flourentzou, N. (2010). On comparing the symmetrical and nonsymmetrical selective harmonic elimination pulse-width modulation technique for two-level three-phase voltage source converters. IET Power Electronics, 3(6): 829-842. https://doi.org/10.1049/iet-pel.2009.0306

[49] Pulikanti, S.R., Agelidis, V.G. (2009). Control of neutral point and flying capacitor voltages in five-level SHEPWM controlled ANPC converter. Proceedings of IEEE ICIEA 2009, pp. 172-177. https://doi.org/10.1109/ICIEA.2009.5138191

[50] Pulikanti, S.R., Agelidis, V.G. (2011). Hybrid flyingcapacitor based active-neutral-point-clamped five-level converter operated with SHE-PWM. IEEE Transactions on Industrial Electronics, 58(10): 4643-4653. https://doi.org/10.1109/TIE.2011.2106098

[51] Pulikanti, S.R., Dahidah, M.S.A., Agelidis, V.G. (2011). Voltage balancing control of three-level active NPC converter using SHE-PWM. IEEE Transactions on Power Delivery, 26(1): 258-267. https://doi.org/10.1109/TPWRD.2010.2063718

[52] Pulikanti, S.R., Konstantinou, G., Agelidis, V.G. (2013). Hybrid seven-level cascaded active-neutral-pointclamped based multilevel converter under SHE-PWM. IEEE Transactions on Industrial Electronics, 60(11): 4794-4804. https://doi.org/10.1109/TIE.2012.2218551

[53] Flourentzou, N., Agelidis, V.G. (2012). Multimodule HVDC system using SHE-PWM with DC capacitor voltage equalization. IEEE Transactions on Power Delivery, $27(1)$ : https://doi.org/10.1109/TPWRD.2011.2167989

[54] Konstantinou, G., Ciobotaru, M., Agelidis, V.G. (2011). Operation of a modular multilevel converter with selective harmonic elimination PWM. Proceedings of IEEE ECCE Asia 2011, pp. 999-1004. https://doi.org/10.1049/iet-pel.2012.0228

[55] Konstantinou, G., Ciobotaru, M., Agelidis, V. (2013). Selective harmonic elimination pulse-width modulation of modular multilevel converters. IET Power Electronics, 6(1): 96-107. https://doi.org/10.1049/iet-pel.2012.0228

[56] Konstantinou, G., Agelidis, V.G., Pou, J (2014). Theoretical considerations for single-phase interleaved converters operated with SHE-PWM. IEEE Transactions on Power Electronics, 29(10): 5124-5128. https://doi.org/10.1109/TPEL.2014.2319826

[57] Sundareswaran, K., Chandra, M. (2002). Evolutionary approach for line current harmonic reduction in AC/DC converters. IEEE Transactions on Industrial Electronics, 49(3):

716-719. 
[58] Dahidah, M.S.A., Agelidis, V.G., Rao, M.V. (2006). On abolishing symmetry requirements in the formulation of a fivelevel selective harmonic elimination pulse-width modulation technique. IEEE Transactions on Power Electronics, 21: 1833-1837. https://doi.org/10.1109/TPEL.2006.883547

[59] Dahidah, M.S.A., Agelidis, V.G. (2008). Nonsymmetrical SHEPWM technique for five-level cascaded converter with nonequal DC sources. Proceedings of 2008 IEEE 2nd International Power and Energy Conference, pp. 775-780. https://doi.org/10.1109/PECON.2008.4762580

[60] Dahidah, M.S.A., Agelidis, V.G., Rao, M.V.C. (2008) Hybrid genetic algorithm approach for selective harmonic control. Energy Conversion and Management, 49(2): $131-142$. https://doi.org/10.1016/j.enconman.2007.06.031

[61] Lou, H., Mao, C., Lu, J., Wang, D., Lee, W.J. (2009). Pulse width modulation AC/DC converters with line current harmonics minimisation and high-power factor using hybrid particle swarm optimisation. IET Power Electronics, 2(6): 686-696. https://doi.org/10.1049/ietpel.2008.0045

[62] Taghizadeh, H., Hagh, M.T. (2010). Harmonic elimination of cascade multilevel inverters with nonequal DC sources using particle swarm optimization. IEEE Transactions on Industrial Electronics, 57(11): 3678-3684. https://doi.org/10.1109/TIE.2010.2041736

[63] Ray, R.N., Chatterjee, D., Goswami, S.K. (2009). Harmonics elimination in a multilevel inverter using the particle swarm optimisation technique. IET Power Electronics, 2(6): 646-652. https://doi.org/10.1049/ietpel.2008.0180

[64] Dorigo, M., Maniezzo, V., Colorni, A. (1996). Ant system: Optimization by a colony of cooperating agents. IEEE Transactions on Systems, Man, and Cybernetics, Part B: Cybernetics, 26(1): 29-41. https://doi.org/10.1109/3477.484436

[65] Dorigo, M., Stützle, T. (2019). Ant colony optimization: overview and recent advances. In: Gendreau M., Potvin JY. (eds) Handbook of Metaheuristics. International Series in Operations Research \& Management Science, Springer, 2nd edition, 272: 227-263. https://doi.org/10.1007/978-1-4419-1665-58

[66] Kar, P.K., Priyadarshi, A., Karanki, S.B. (2019). Selective harmonics elimination using whale optimisation algorithm for a single-phase-modified source switched multilevel inverter. IET Power Electronics, $12(8)$ : 1952-1963 https://doi.org/10.1049/iet-pel.2019.0087

[67] Ray, R.N., Chatterjee, D., Goswami, S.K. (2009). Harmonics elimination in a multilevel inverter using the particle swarm optimisation technique. IET Power Electronics, 2(6): 646-652. https://doi.org/10.1049/ietpel.2008.0180

[68] Taghizadeh, H., Hagh, M.T. (2010). Harmonic elimination of cascade multilevel inverters with nonequal DC sources using particle swarm optimization. IEEE Transactions on Industrial Electronics, 57(11): 3678-3684. https://doi.org/10.1109/TIE.2010.2041736

[69] Napoles, J., Watson, A.J., Padilla, J.J., Leon, J.I., Franquelo, L.G., Wheeler, P.W. (2013). Selective harmonic mitigation technique for cascaded $\mathrm{H}$-bridge converters with non-equal DC link voltages. IEEE
Transactions on Industrial Electronics, 60(5): $1963-$ 1971. https://doi.org/10.1109/TIE.2012.2192896

[70] Marzoughi, A., Iman-Eini, H. (2012). Selective harmonic elimination for cascaded $\mathrm{H}$-bridge rectifiers based on indirect control. Proceedings of PEDSTC, pp. 79-85. https://doi.org/10.1109/PEDSTC.2012.6183302

[71] Dahidah, M.S.A., Agelidis, V.G. (2008). Single-carrier sinusoidal PWM-equivalent selective harmonic elimination five-level inverter control. Electric Power Systems Research, 78(11): 1826-1836. https://doi.org/10.1016/j.epsr.2008.01.021

[72] Agelidis, V.G., Balouktsis, A., Dahidah, M.S.A. (2008). A fivelevel symmetrically defined selective harmonic elimination PWM strategy: Analysis and experimental validation. IEEE Transactions on Power Electronics., 23(1):

19-26. https://doi.org/10.1109/TPEL.2007.911770

[73] Dahidah, M.S.A., Konstantinou, G., Agelidis, V.G. (2012). Selective harmonic elimination pulse-width modulation sevenlevel cascaded H-bridge converter with optimised DC voltage levels. IET Power Electronics, 5(6): 852-862. https://doi.org/10.1049/iet-pel.2011.0463

[74] Vassallo, J., Clare, J.C., Wheeler, P.W. (2003). A powerequalized harmonic-elimination scheme for utilityconnected cascaded Hbridge multilevel converters. Proceedings of IEEE IECON 2003, pp. 1185-1190. https://doi.org/10.1109/IECON.2003.1280221

[75] Watson, A.J., Wheeler, P.W., Clare, J.C. (2007). A selective harmonic elimination system for restoring and equalising DC link voltages in a multilevel active rectifier. Proceedings of EPE 2007, pp. 1-7. https://doi.org/10.1109/EPE.2007.4417394

[76] Xu, L., Agelidis, V.G. (2005). A VSC transmission system using flying capacitor multilevel converters and selective harmonic elimination PWM control. Proceedings of IEEE IPEC 2005, Singapore, pp. 11761181. https://doi.org/10.1109/IPEC.2005.207085

[77] Xu, L., Agelidis, V.G. (2007). VSC transmission system using flying capacitor multilevel converters and hybrid PWM control. IEEE Transactions on Power Delivery, 22(1): 693-702. https://doi.org/10.1109/TPWRD.2006.883003

[78] Saeedifaard, M., Nikkhajoei, H., Iravani, R., Bakhshai, A. (2007). A space vector modulation approach for a multimodule HVDC converter system. IEEE Transactions on Power Delivery, 22(3): 1643-1654. https://doi.org/10.1109/PES.2007.385593

[79] Ilves, K., Antonopoulos, A., Norrga, S., Nee, H.P. (2011). A new modulation method for the modular multilevel converter allowing fundamental switching frequency. Proceedings of IEEE ECCE Asia 2011, pp. 991-998. https://doi.org/10.1109/ICPE.2011.5944672

[80] Wang, Y.X., Wen, X.H., Zhao, F., Guo, X.H. (2012). Selective harmonic elimination PWM technology applied in PMSMs. Proceedings of VPPC, Seoul, Korea, pp. 92-97. https://doi.org/10.1109/VPPC.2012.6422564

[81] Liu, W.H., Song, Q., Xie, X.R., Chen, Y.H., Yan, G.G. (2003). 6kV/1800kVA medium voltage drive with threelevel NPC inverter using IGCTs. Proceedings of IEEE APEC, Miami Beach, Florida, USA, pp. 223-227. https://doi.org/10.1109/APEC.2003.1179219

[82] Zhang, Y.C., Zhao, Z.M., Zhu, J.G. (2011). A hybrid PWM applied to high power three-level inverter-fed induction-motor drives. IEEE Transactions on Industrial 
Electronics, 58(8):

$3409-3420$

https://doi.org/10.1109/TIE.2010.2090836

[83] Wu, B., Dewan, S.B., Slemon, G.R. (1992). PWM-CSI inverter for induction motor drives. IEEE Transactions on Industrial Appllications, 28(1): 64-71. https://doi.org/10.1109/IAS.1989.96698

[84] Du, Z., Ozpineci, B., Tolbert, L.M., Chiasson, J.M. (2009). DC-AC cascaded H-bridge multilevel boost inverter with no inductors for electric/hybrid electric vehicle applications. IEEE Transactions on Industrial Electronics, 45(3): 963-970. https://doi.org/10.1109/TIA.2009.2018978

[85] Li, Y.W., Pande, M., Zatgari, N.R., Wu, B. (2010). An input power factor control strategy for high-power current-source induction motor drive with active frontend. IEEE Transactions on Power Electronics, 25(2): 352-359. https://doi.org/10.1109/TPEL.2009.2028344

[86] Flourentzou, N., Konstantinou, G., Agelidis, V.G. (2010). DC-bus capacitorless rectifier-inverter motor drive with online optimized harmonic controlled PWM. Proceedings of IEEE ICIT 2010, Viña del Mar, Valparaiso, Chile, pp. 344-349. https://doi.org/10.1109/ICIT.2010.5472704.

[87] Gültekin, B., Gerçek, C.O., Atalik, T., Deniz, M., Biçer, N., Ermis, M., Kose, N., Ermis, C., Koç, E., Çadirci, I., Açik, A., Akkaya, Y., Toygar, H., Bideci, S. (2010). Design and implementation of a $154-\mathrm{Kv}, \pm 50-\mathrm{MVAr}$ transmission STATCOM based on 21-level cascaded multilevel converter. 2010 IEEE Energy Conversion Congress and Exposition, Atlanta, GA, pp. 3936-3948. https://doi.org/10.1109/ECCE.2010.5617795
[88] Flourentzou, N., Agelidis, V.G. (2012). Multimodule HVDC system using SHE-PWM with DC capacitor voltage equalization. IEEE Transactions on Power Delivery, 27(1):

79-86. https://doi.org/10.1109/TPWRD.2011.2167989

\section{NOMENCLATURE}

SHE Selective Harmonic Elimination

HE Harmonic Elimination

MSHE Multilevel Selective Harmonic Elimination

QW Quarter Wave

HW Half Wave

THD Total Harmonic Distortion

QWS Quarter Wave Symmetry

HWS Half Wave Symmetry

GA Genetic Algorithm

PSO Particle Swarm Optimization

ACO Ant Colony Optimization

WAO Whale Optimization

PV Photo Voltaic

HVDC High Voltage Direct Current

FACTS Flexible AC Transmission Systems

MMC Modular Multilevel Converter

FC Flying Capacitor

NPC Neutral Point Clamping

CHB Cascaded H-bridge

MLI Multi Level Inverter

ANPC Active Neutral Point Clamping 